\title{
INDUÇÃO DE EMBRIOGÊNESE SOMÁTICA EM CUPUAÇU (Theobroma grandiflorum Schum.) ${ }^{1}$
}

\author{
MARIA DAS GRAÇAS RODRIGUES FERREIRA², CARLOS HENRIQUE SIQUEIRA DE CARVALHO², \\ ANDRÉIA DE ALMEIDA CARNEIRO ${ }^{4}$, CARLOS FERREIRA DAMIÃO FILHO ${ }^{5}$
}

\begin{abstract}
RESUMO - Folhas jovens de cupuaçu (Theobroma grandiflorum Schum.) foram empregadas para indução de embriogênese somática, as quais foram cultivadas inicialmente em meio MS suplementado com 6,0 mg/L BAP e 0,5 mg/L AIA (meio de estabelecimento), seguindo-se o cultivo em meio MS suplementado com 2,20 mg/L TDZ (meio de indução). A região da nervura mostrou intumescimento três dias após inoculação no meio de estabelecimento, o qual foi seguido pela formação de cachos de calos. As massas calosas foram transferidas para o meio de indução, e as estruturas com características pró-embriogênicas puderam ser observadas após uma semana. Estudos de microscopia eletrônica de varredura revelaram estruturas com características de embriões somáticos no meio com TDZ.
\end{abstract}

Termos para indexação: Theobroma grandiflorum, embrião somático, TDZ.

\section{INDUCTION OF SOMATIC EMBRYOGENESIS IN CUPUASSU (Theobroma grandiflorum Schum.)}

\begin{abstract}
Young leaves of cupuassu (Theobroma grandiflorum Schum.) were used to induce somatic embryogenesis, which were cultivated initially in MS basal medium suplemented with $6.0 \mathrm{mg} / \mathrm{L}$ BAP and $0.5 \mathrm{mg} / \mathrm{L}$ IAA (established medium ) followed by MS basal medium supplemented with 2,20 mg/L TDZ (induction medium). Vascular region of explants showed intumescement three days after inoculation in established medium, which was followed by the formation of calli clusters. Calli mass were transferred to induction medium, and the structures with proembryogenic characteristics could be observed after one week. Scanning electron microscopy studies revealed structures with somatic embryos characteristics in the medium with TDZ.
\end{abstract}

Index terms: Theobroma grandiflorum, somatic embryos, TDZ

Abbreviations: MS: Murashige and Skoog (1962), BAP: Benzylaminopurine, IAA: indol-acetic acid, TDZ: thidiazuron, SEM: Scanning electron microscopy.

O cupuaçuzeiro (Theobroma grandiflorum Schum.) é uma das fruteiras mais atrativas da região amazônica, devido às características de sabor e aroma de sua polpa, que é empregada na fabricação de sucos, sorvetes, licores, compotas, geléias, cremes, doces, etc. Nas ultimas três décadas, com o aumento da demanda, o cupuaçuzeiro passou por um processo de transição do extrativismo para a forma cultivada, emergindo nos últimos anos com o aumento da área plantada e com a ampliação do cultivo para outras regiões brasileiras (Embrapa, 1999).

O cupuaçuzeiro pode atingir $15 \mathrm{~m}$ de altura e 6 a 8 m de diâmetro de copa (Venturieri et al., 1985). É uma espécie tricômica, ou seja, cada lançamento (ramo) se divide em três, que crescem quase em paralelismo com o solo. Da axila desses galhos, surge um broto que retoma o crescimento vertical e assim por diante. As folhas, quando jovens, são de cor rósea e revestidas de pêlos, atingindo em seu estágio final de 25 a $30 \mathrm{~cm}$ de comprimento por 10 a $15 \mathrm{~cm}$ de largura, adquirindo tonalidade verde-escura. As flores desenvolvem-se nos ramos mais periféricos, sendo o cupuaçuzeiro uma espécie de polinização cruzada (alógama), com possibilidades de autofecundação (Ribeiro, 1995). A espécie possui um elevado índice de abortamento floral, pois a planta produz aproximadamente 3.500 flores, com produção média de frutos de 17,2. Entretanto, em termos de eficiência energética, a produção de aproximadamente $16,0 \mathrm{~kg}$ de frutos por árvore assemelha-se a outras espécies de fruteiras tropicais (Falcão e Lleras,1983).

O fruto do cupuaçu, também chamado de “cupu”, mede de 12 a $25 \mathrm{~cm}$ de comprimento e 10 a $12 \mathrm{~cm}$ de diâmetro, apresentando em média peso de 1,0 kg, 30 a 40\% de polpa e 35 sementes - 15 a 20\% do fruto (Fraife Filho, s.d.). Constitui-se de uma baga drupácea, elipsóide, com extremidades obtusas ou arredondadas (Venturieri et al., 1985), o que diferencia as variedades. Sua casca é dura e lenhosa, coberta de indumento ferrugíneo, equivalente a $40-50 \%$ do peso do fruto (Ribeiro, 1995), podendo ser empregada como ração para gado e adubo, semelhante à utilização da casca de cacau.
As mudas produzidas são, na sua maioria, provenientes de sementes, sem uma prévia seleção da planta-matriz, ocasionando a formação de plantio com elevada variabilidade quanto à produção e formato dos frutos, arquitetura de copa, formato das folhas, entre outros (Alves et al., 1998). Instituições de pesquisas na região Norte têm implementado programas de melhoramento com ênfase na seleção de materiais com características de alta produção de frutos, rendimento de polpa e resistência à vassoura-de-bruxa (Crinipellis perniciosa), principal enfermidade da cultura. Clones de cupuaçuzeiro foram introduzidos no Banco Ativo de Germoplasma de Cupuaçuzeiro da Embrapa Amazônia Oriental, em Belém, oriundos de coletas de borbulhas e ponteiras realizadas nos Estados do Amapá, Amazonas e Pará nos anos 80. Após as avaliações de campo, selecionaram-se quatro clones com boa produtividade e tolerância à vassoura-de-bruxa: Coari, Codajás, Manacapuru e Belém (Cruz e Alves, 2002).

A embriogênese somática é um importante método de regeneração usado para propagação de plantas-elite in vitro, em larga escala, sendo também uma estratégia para os estudos básicos relacionados com a fisiologia do desenvolvimento do embrião. De acordo com MERKLE (1995), a embriogênese somática é, teoricamente, a melhor opção para a propagação in vitro de fruteiras, devido às seguintes vantagens: 1 ) alta taxa de multiplicação comparada a qualquer outro processo de propagação; 2) escalonamento da produção pela manutenção da cultura em meio líquido, eliminando a dependência de períodos específicos de disponibilidade de material propagativo, permitindo estabelecer o período desejado para as obtenções; 3) plantio direto da muda obtida via embriogênese somática sem necessidade de enxertia, com menor custo de produção, além de a planta ser geneticamente igual à planta-mãe, sem as influências do porta-enxerto, como acontece com as plantas obtidas por métodos de propagação vegetativa convencionais; e, mais importante para o melhoramento per se; 4) possibilita a transferência de genes, razão pela qual tem sido utilizada como ferramenta em estudos de desenvolvimento das plantas

\footnotetext{
${ }^{1}$ (Trabalho 079/2004). Recebido: 27/05/2004. Aceito para publicação: 06/10/2005. Parte da Tese de Doutorado do primeiro autor

2 Dra., Pesquisadora da Embrapa Rondônia, BR 364 - km 5,5 - Caixa Postal 406 - Porto Velho - RO. CEP - 78.970-900 e-mail: mgraca@cpafro.embrapa.br

${ }^{3}$ Fundação Pró-café, Alameda do Café, 1000, CEP - 37026-400, Varginha -MG. e-mail: carlos@varginha.br

${ }^{4}$ Embrapa Milho e Sorgo, Núcleo de Biologia Aplicada, Cx Postal 151. CEP - 35701-970, Sete Lagoas-MG.

${ }^{5}$ Depto. de Biologia Aplicada à Agropecuária, FCAV-UNESP, Via de Acesso Prof. Paulo Donato Castellane, Km 05, CEP- 14870-000, Jaboticabal-SP.
} 
(ZIMMERMAN, 1993), propagação clonal e melhoramento, tanto pela fusão de protoplastos como pela transformação genética.

O entendimento do processo de embriogênese somática desta espécie, além de auxiliar a produção de plantas-elite, pode servir como base para futuros trabalhos de melhoramento, visando à produção de plantas resistentes a moléstias, como a vassoura-de-bruxa, através da manipulação de DNA, alta produção de frutos, rendimento de polpa e curto período de armazenamento do fruto. Os estudos de propagação in vitro para o gênero Theobroma têm-se limitado à espécie Theobroma cacao L., considerada até há pouco tempo como a única espécie do gênero cultivada comercialmente. Assim, devido à proximidade botânica com o cacau, espera-se que protocolos possam ser adaptados para o cupuaçu. O objetivo deste trabalho foi desenvolver protocolos para indução de embriões somáticos de cupuaçu, visando à obtenção de plantas sadias que serão usadas em futuros programas de melhoramento genético, bem como testar o potencial morfogenético de folhas de cupuaçuzeiro.

\section{Local do experimento}

O experimento foi conduzido no Laboratório de Biologia Celular do Núcleo de Biologia Aplicada, pertencente à Embrapa Milho e Sorgo, Sete Lagoas-MG.

\section{Fonte de explante}

Foram empregadas folhas de mudas obtidas por sementes de cupuaçu da variedade Mamorana. O material foi adquirido junto ao Centro de Pesquisa da Lavoura Cacaueira (CEPLAC), Itabuna, Bahia.

\section{Preparo dos explantes}

Foram empregadas folhas jovens totalmente expandidas, ainda flácidas, coletadas após a tonalidade avermelhada ter desaparecido. As folhas passaram por uma pré-limpeza, que consistiu de imersão em água destilada, contendo algumas gotas de detergente comercial; em água corrente, as mesmas foram esfregadas, a fim de retirar as impurezas e os pêlos. A seguir, folhas inteiras foram esterilizadas com $20 \%$ de hipoclorito de sódio (alvejante comercial), contendo 3 gotas de Tween 20, durante 20 minutos. As folhas foram lavadas 3 vezes com água bidestilada estéril e cortadas em quadrados de aproximadamente 1 x 1 $\mathrm{cm} 2$.

\section{Meios de cultura empregados}

Os explantes foram cultivados em placas de Petri descartáveis (90 x $15 \mathrm{~mm}$ ) e mantidos em sala de crescimento, intercalando luz e escuro a $28^{\circ} \mathrm{C}$. Para cada condição, foram feitas 10 repetições, empregando os seguintes meios:

- Meio de estabelecimento: sais MS (50\%) (SIGMA) (2,15 g/L) e vitaminas MS (1000 x) (1 ml/L), sacarose (3\%), suplementados com BAP (6,0 mg/L), AIA (0,5 mg/L), semi-solidificado com ágar (8 g/L) e pH 6,0 antes da autoclavagem;- Meio de indução: sais MS (50\%) (SIGMA) (2,15 g/L), vitaminas MS (1000 x) (1 ml/L), TDZ (2,20 mg/L), sacarose (30 g/L), ágar (8g/L) e pH 6,0 antes da autoclavagem; - Meio de regeneração: sais MS, vitaminas LS (25 mg/L ácido nicotínico, $25 \mathrm{mg} / \mathrm{L}$ piridoxina, 50 $\mathrm{mg} / \mathrm{L}$ tiamina - HCL), sacarose (6\%), mioinositol (100 mg/L), ANA(0,4 $\mathrm{mg} / \mathrm{L}$ ), phytagel (3 g/L) e pH 5,8.

\section{Estudo em microscopia eletrônica de varredura}

As estruturas formadas foram fixadas a $4^{\circ} \mathrm{C}$ em glutaraldeído a

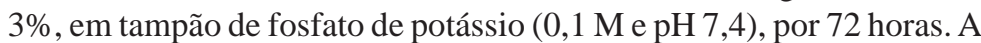
seguir, o material foi lavado em solução tampão pura por cinco vezes consecutivas, por 15 minutos, e pós-fixado em tetróxido de ósmio a $2 \%$, no mesmo tampão e na mesma temperatura, por cerca de 12 horas. Na seqüência, foi novamente lavado, como no caso anterior, desidratado em série gradual de etanol, seco em secador de ponto crítico com $\mathrm{CO}_{2}$, montado, metalizado com $35 \mathrm{~nm}$ de ouro-paládio, observado e elétronmicrografado em microscópio eletrônico de varredura JEOL JSM 5410,

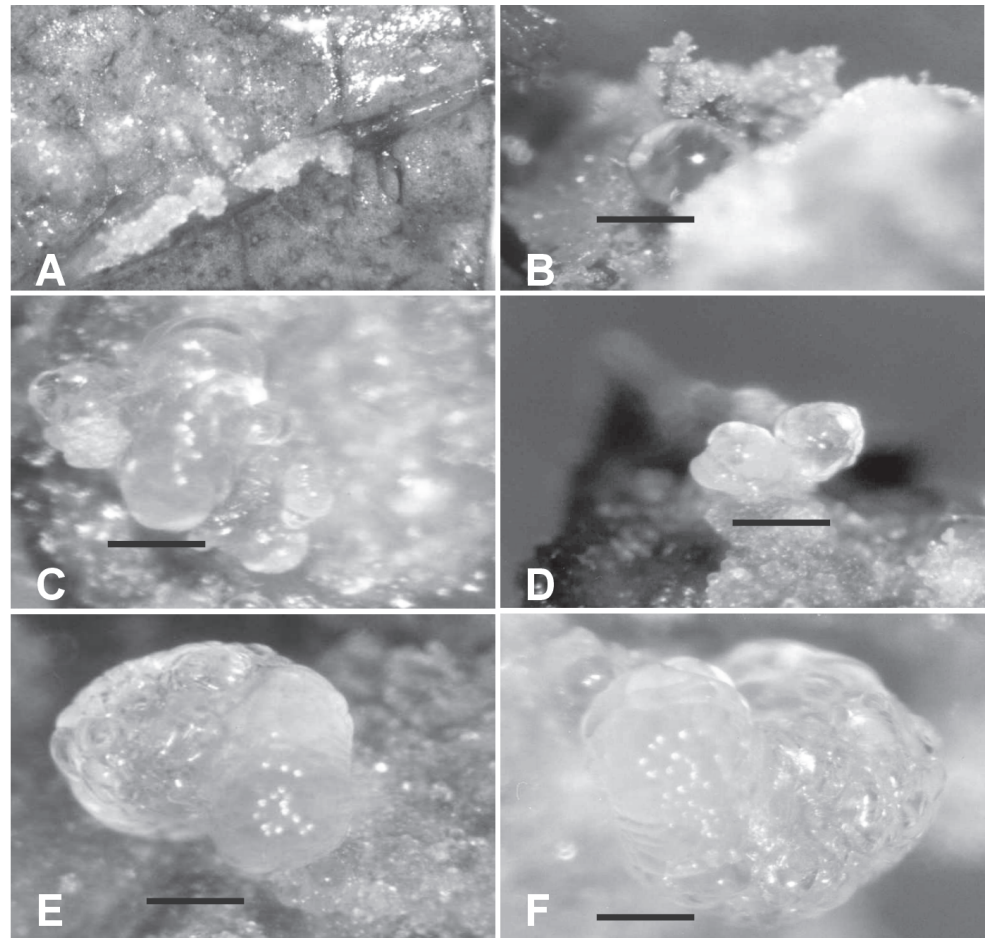

FIGURA 1 - Seqüência de desenvolvimento de estruturas em tecido foliar de cupuaçu. A) Formação de massa calosa em segmento foliar, na região da nervura principal; B) Início de formação de estrutura com aparência pró-embriogênica na massa calosa; C) Estruturas em forma de cachos; D) Estrutura com aspecto globular; E,F) Detalhes da estrutura (barra horizontal $=2 \mathrm{~mm}$ )

operado em $15 \mathrm{KV}$.

Os segmentos foliares apresentaram intumescimento na região das nervuras, 3 dias após a inoculação no meio de estabelecimento, seguindo-se o aparecimento de calos dentro de uma semana, nessa região (Figura 1A). Resultados semelhantes foram obtidos por ABRAHAM et al. (1992), empregando folhas tenras de cacau, com o objetivo de padronizar um meio de cultura adequado para propagação vegetativa rápida através da embriogênese somática.

Os calos foram mantidos no meio de estabelecimento, durante 5 semanas, sendo subcultivados a cada duas semanas. Durante esse período, notou-se a proliferação de massa calosa em todo o explante, em forma de cachos, que murchavam, não ultrapassando esse estádio. SEARLES e ALVIM (1976), utilizando segmentos foliares e partes de fruto imaturo de Theobroma cacao, concluíram que tecidos foliares requerem somente uma citocinina para proliferação celular, sendo que esses tecidos são aparentemente auto-suficientes em auxina e, na maioria dos casos, a sua presença no meio de cultura foi inibitória para proliferação de calos.

Em seguida, os explantes foram transferidos para o meio de indução, que continha TDZ. Após uma semana neste meio, verificou-se maior proliferação de calos e, em seguida, ocorreu a diferenciação de estruturas com aparência pró-embriogênica na massa calosa. Estas tinham um aspecto globular, transparente e tornavam-se mais densas, à medida que cresciam (Figura 1B, C, D, E e F). Estruturas semelhantes foram verificadas por SHATTERS et al. (1994) em calos de Paspalum notatum Fluegge L.

Estruturas semelhantes a embrióides apareceram em pequenos grupos ou em forma de cachos sobre a superfície de tecido foliar cultivado em meio com TDZ (Figura 2A, B). Duas semanas após a inoculação neste meio, verificou-se a formação de estruturas semelhantes a embriões somáticos no estágio globular, ligadas ao tecido do explante por um suspensor (Figura 2C, D). Embrióides de cacau, apresentando estruturas semelhantes a um suspensor, também foram observadas por ESAN (1977), PENCE et al. (1980) e KONONOWICZ et al. (1984). 


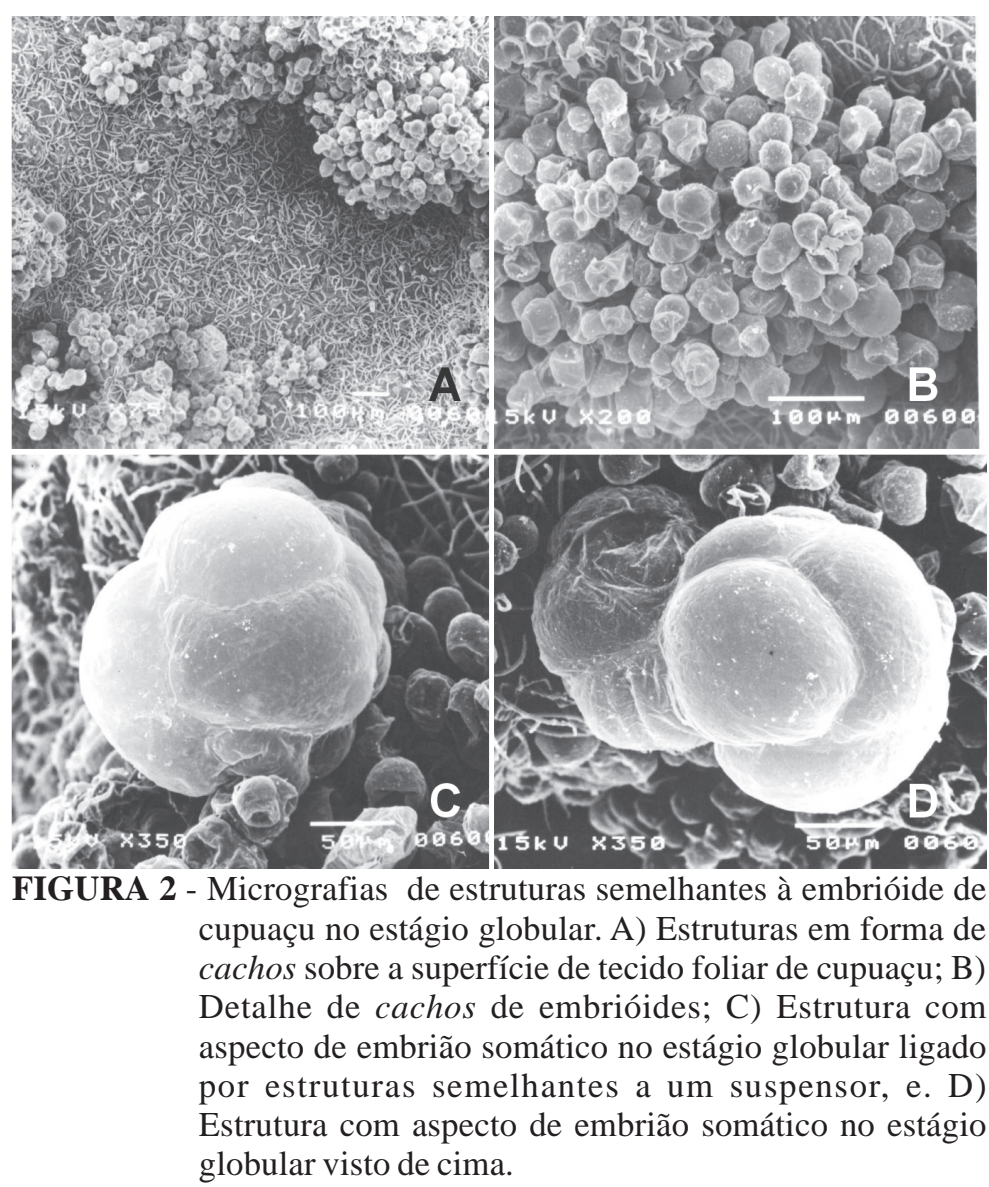

As culturas foram subcultivadas a cada 15 dias nesse meio, durante dois meses. Em seguida, as mesmas foram transferidas para o meio de regeneração, a fim de estimular o completo desenvolvimento do embrião. Uma semana após transferência para o meio de regeneração, observou-se que as estruturas estavam mais densas, com aspecto mais escuro e secaram. Assim, não foi possível estimular o desenvolvimento dos embriões somáticos além desse estágio; contudo, ficou demonstrado o potencial morfogenético de folhas de cupuaçu. WANG e JANICK (1984) demonstraram que é possível estimular a germinação precoce dos embriões de cacau pela lavagem sucessiva dos embriões somáticos ou pela remoção do meio de cultura.

O aparecimento dessas estruturas pode ser devido à inclusão de TDZ no meio de cultura, um substituto da feniluréia comumente usado como desfolhante (ARNDT et al.,1976), mas que tem mostrado exibir forte atividade, semelhante à citocinina. GILL e SAXENA (1992) induziram e conduziram o desenvolvimento de embriões somáticos, a partir de segmentos foliares e cotilédones de Arachis hypogaea, cultivados em meio MS, com várias concentrações de TDZ (1; 5; 10; 15; 20 ou $25 \mu \mathrm{M})$ e meio MS acrescido de BAP $(30 \mu \mathrm{M})$. Observaram que a aplicação de BAP como único regulador de crescimento promoveu apenas regeneração de broto, enquanto o uso de TDZ $10 \mu \mathrm{M}$ foi a concentração mais adequada para a indução da embriogênese somática. Os autores sugerem que a indução da embriogênese somática em culturas de folhas e segmentos cotiledonares de amendoim pelo uso de TDZ pode, em parte, ser devida ao envolvimento de uma auxina.

THOMAS e KATTERMAN (1986) informaram que as auxinas críticas para indução de embriões podem ser sintetizadas pelo tecido cotiledonar ou foliar tratado com TDZ em modelo similar àquele descrito pela biossíntese de citocininas induzidas pelo TDZ. LI et al. (1998) relataram um procedimento para embriogênese somática e regeneração de plantas, a partir de tecidos florais de cacau. Foi empregado o meio DKW suplementado com 20 g/L de glicose, 9 mM de 2,4-D e TDZ em várias concentrações. 22,7 nM de TDZ promoveram a mais alta taxa de proliferação de calos, freqüência de embriogênese e número de embriões somáticos/explante.

Os resultados com a micropropagação dessa espécie do gênero
Theobroma ainda são incipientes, não se dispondo de protocolos que possibilitem a obtenção de plantlets. Tentativas com a embriogênese somática possibilitaram apenas a obtenção de calos embriogênicos que falharam na produção de seedlings viáveis (VELHO et al., 1990). Alguns trabalhos têm mostrado a capacidade de diferentes explantes de cupuaçuzeiro em formar calos. FERREIRA et al. (2001), avaliando o efeito de auxinas, observaram que a combinação de ANA e 2,4-D induziu a rizogênese e a formação de calos em segmentos de hipocótilo, e a água de coco, em meio sem reguladores de crescimento, favoreceu a rizogênese e a calogênese.

Rodrigues (2000) não verificou a formação de calos em segmentos nodais de cupuaçu em meio suplementado com diferentes concentrações de 2,4 D. Ledo et al. (2002) avaliaram as respostas morfogenéticas de diferentes explantes de cupuaçuzeiro submetidas a várias condições de cultura in vitro. Os autores afirmam que a ausência de indução de calos embriogênicos observada nas culturas pode estar relacionada com diversos fatores, como tipo e o estádio de desenvolvimento dos explantes, meio de cultura e tipo e concentração de reguladores de crescimento. Assim, devido ao alto potencial econômico dessa espécie, pesquisas básicas são necessárias para estimular a germinação e o desenvolvimento de embriões somáticos, visando à produção de plantas-elite, que possam superar problemas, como a alta suscetibilidade à vassoura-de-bruxa, curto período de armazenamento do fruto e rendimento de polpa.

- Ficou demonstrado o potencial morfogenético de folhas de cupuaçu.

- Aparecimento de estruturas embriogênicas pode ser devido à inclusão de TDZ no meio de cultura.

- Há necessidade de mais estudos para estimular a germinação e o desenvolvimento de embriões somáticos de cupuaçu, testando-se outras doses de TDZ, que se mostrou eficiente na diferenciação da aparência dos calos, e outros tipos de explante, como partes florais e tecido nucelar.

\section{REFERÊNCIAS}

ABRAHAM, P.; SAJI, K.V.; IYER, R.D. In vitro studies on cacao (Theobroma cacao L.) somatic embryogenesis from cotyledon explants. Journal of Plantation Crops, Kerala, v. 20, n. 2, p. 110113, 1992.

ALVES, R.M.; CORRÊA, J.R.V.; GOMES, M.R.O. Avaliação preliminar de clones de cupuaçuzeiro (Theobroma grandiflorum), em áreas de produtores de Tomé-Açu-PA. In: ENCONTRO DE GENÉTICA DO NORDESTE, 13., 1998, Feira de Santana. Anais... Feira de Santana: UEFS, 1998. p.359.

ARNDT, F.; RUSCH, R.; STILFRIED, H.V SN 49537, a new cotton defoliant. Plant Physiology, Rockville, v.57, suppl., p.99, 1976.

CRUZ, E. D.; ALVES, R. M. Clones de cupuaçuzeiro tolerantes à vassoura-de-bruxa. Belém: Embrapa Amazônia Oriental, 2002. 4p.

EMBRAPA AMAZÕNIA ORIENTAL. Programa de melhoramento genético e de adaptação de espécies vegetais para a Amazônia Oriental. Belém, 1999. 137p. (Documentos, 16).

ESAN , E. B. Régénération des pousses à partir de calle provenant de cultures axillaires d'embryons de Theobroma cacao in vitro. In: CONFERÊNCIA INTERNACIONAL SOBRE PESQUISAS CACAUEIRAS, 4., 1977, Ilhéus. Anais... Ilhéus: CEPLAC, 1977. p.5567.

FALCÃO, M.A.; LLERAS, E. Aspectos fenológicos, ecológicos e de produtividade do cupuaçu (Theobroma grandiflorum (Willd ex Spreng) Schum.). Acta Amazônica, Manaus, v.13, n.5-6, p.725735.1983.

FERREIRA, M.G.R.; CÁRDENAS, F.E.N.; CARVALHO, C.H.S.; CARNEIRO, A.A.; DAMIÃO FILHO, C.F. Desenvolvimento de calos em explantes de cupuaçuzeiro (Theobroma grandiflorum Schum) em função da concentração de auxinas e do meio líquido. Revista Brasileira de Fruticultura, Jaboticabal, v. 23, n. 1, p. 473- 
476, 2001.

FRAIFE, G.A. Alternativas para diversificação agroeconômica da região Sudeste da Bahia. Ilhéus: CEPLAC, 1984. (Seção de Diversificação).

GILL, R.; SAXENA, P.K. Direct somatic embryogenesis and regeneration of plants from seedling explants of peanut (Arachis hypogaea): promotive role of thidiazuron. Canadian Journal of Botany, Ottawa, v. 70, p. 1186-1192, 1992.

KONONOWICZ, H.; KONONOWICZ, A.K.; JANICK, J. Asexual embryogenesis via callus of Theobroma cacao L. Zeitschrift für Pflanzenphysiologie, Stuttgart, v. 113, n. 4, p. 347-358, 1984.

LEDO, A.S.; LAMEIRA, O.A.; BENBADIS, A.K. Explantes de cupuaçuzeiro submetidos a diferentes condições de cultura in vitro. Revista Brasileira de Fruticultura, Jaboticabal, v. 24, n. 3, p.604607, 2002.

LI, Z.; TRAORE, A.; MAXIMOVA, S.; GUILTINAN, M. J. Somatic embryogenesis and plant regeneration from floral explants of cacao (Theobroma cacao L.) using thidiazuron. In vitro Cell Development Plant, Oxon, v.34, p. 293-299, 1998.

MERKLE, S.A.; PARROTT, W.A.; FLINN, B.S. Morphogenic aspects of somatic embryogenesis. In: THORPE, T.A. (Ed.). In vitro embryogenesis in plants. Dordrecht: Kluwer Academics, 1995. p.155-203.

MÜLLER, C.H.; CARVALHO, J.E.U. Sistemas de propagação e técnicas de cultivo do cupuaçuzeiro (Theobroma grandiflorum). In: SEMINÁRIO INTERNACIONAL SOBRE PIMENTA-DO-REINOE CUPUAÇU, 1., 1996, Belém-PA. Anais... Belém: Embrapa Amazônia Oriental/JICA, 1997. 440p. (Documentos, 89).

PENCE, V.C.; HASEGAWA, P.M.; JANICK, J. Initiation and developement of asexual embryos of Theobroma cacao L. in vitro. Zeitschrift für Pflanzenphysiologie, Stuttgart, v. 98, n.1, p. 1-14, 1980.
RIBEIRO, G.D. A cultura do cupuaçuzeiro em Rondônia. Porto Velho: EMBRAPA-CPAF-Rondônia, 1995. 32p. (Documentos, 27).

RODRIGUES, E.F. Desenvolvimento do eixo embrionário in vitro e calogênese de cupuaçu (Theobroma grandiflorum (Willd. ex Spreng.) Schum.) e estabelecimento do ápice caulinar de bacuri (Platonia insignis Martius). 2000. 70f. Tese (Doutorado em Agronomia)- Faculdade de Ciências Agrárias e Veterinárias, Universidade Estadual Paulista, Jaboticabal, 2000.

SEARLES, B.R.; ALVIM, P.T.; SHARP, W. R. Hormonal control of cellular proliferation in cultured callus derived from Theobroma cacao L. Revista Theobroma, Ilhéus, v. 6, n. 3, p.77-81, 1976.

SHATTERS, J.R.R.G.; WHEELER, R.A.; WEST, S.H. Somatic embryogenesis and plant regeneration from callus cultures of “Tifton 9” Bahiagrass. Crop Science, Madison, v. 34, p. 1.378-1.384, 1994.

THOMAS, J.C.; KATTERMAN, F.R. Cytokinin activity induced by thidiazuron. Plant Physiology, Rockville, v.81, p.681-683, 1986.

VELHO, C.C.; WHIPKEY, A.; JANICK, J. Cupuassu: a new beverage crop for Brazil. In: JANICK, J.; SIMON, J. E. Advances in new crops. Portland: Timber Press, 1990. p. 372-375.

VENTURIERI, G.A; ALVES, M.L.B.; NOGUEIRA, M.Q. O Cultivo do cupuaçuzeiro. Informativo SBF, Campinas, v.4, n.1,p.15-17, 1985.

WANG, Y.; JANICK, J. Inducing precocious germination in asexual embryos of cacao. HortScience, Alexandria, v. 19, n. 6, p. 839-841, 1984.

ZIMMERMAN, J.L. Somatic embryogenesis: a model for early development in higher plants. Plant Cell, Dordrecht, v. 5, p. 14111423, 1993. 